\title{
Urinary TWEAK; Diagnostic and Prognostic Biomarker in Evaluating Lupus Nephritis Case Control Study Nahla M. Gaballah ${ }^{1}$, Yomna A. Amer ${ }^{1}$, Lamiaa M. Kamel*2, Salem A. El-Deeb ${ }^{3}$, Abeer M. El-Shafey ${ }^{1}$. \\ Departments of ${ }^{1}$ Rheumatology and Rehabilitation, ${ }^{2}$ Clinical Pathology and \\ ${ }^{3}$ Internal Medicine, Faculty of Medicine, Zagazig University, Egypt. \\ *Corresponding author: Lamiaa M. Kamel, Mobile: (+20) 01118631133, Email: lamneg@ gmail.com
}

\begin{abstract}
Background: Tumor necrosis factor-like weak inducer of apoptosis (TWEAK) is a multifunctional cytokine that belongs to the TNF-ligand superfamily.

Objective: To evaluate the ability of urinary TWEAK (uTWEAK) to diagnose lupus nephritis (LN) and its correlation with activity and chronicity index.

Patients and Methods: This study was carried out on 75 individuals, 50 SLE patients, fulfilling the SLICC revision of the ACR classification criteria for SLE and 25 age and sex matched apparently healthy control subjects. Patients were assessed by SLE disease activity index (SLEDAI-2K) score. Renal biopsy were done for SLE patients who have confirmed proteinuria $>0.5 \mathrm{~g}$ in 24-hour urine samples or active urinary sediment or inexplicable decrease in renal function. Urinary TWEAK levels were measured by ELISA.

Results: UTWEAK level showed a highly statistical significant difference among groups $(\mathrm{P}<0.001)$. There was direct highly significant correlations between uTWEAK and total $(\mathrm{t})$ SLEDAI $(\mathrm{r}=0.58, \mathrm{P}<0.001)$ and renal (r)SLEDAI $(\mathrm{r}=0.73, \mathrm{P}<0.001)$. uTWEAK had significant association with the presence of proliferative GN (Class III, IV) $(\mathrm{p}=$ 0.003 ). At cutoff point $\geq 9.9 \mathrm{pg} / \mathrm{mg}$ Cr, uTWEAK had sensitivity of $76 \%$ and a specificity of $60 \%$ to diagnose SLE patients with nephritis. At cutoff point of $\leq 14.9 \mathrm{pg} / \mathrm{mg} \mathrm{Cr}$, the uTWEAK level had a sensitivity of $88 \%$ and a specificity of $76 \%$ to predict good response to treatment in LN patients.

Conclusion: We concluded that UTWEAK is a candidate biomarker for evaluating LN. It possesses numerous properties that make it suitable for assessment of LN activity and prognosis.
\end{abstract}

Keywords: Diagnostic and Prognostic Biomarker, Lupus Nephritis, Urinary TWEAK.

\section{INTRODUCTION}

Systemic lupus erythematosus (SLE) is a clinical syndrome of inflammatory autoimmune disease characterized by multisystem involvement and fluctuating disease activity. Symptoms range from rather mild manifestations such as rash or arthritis to life-threatening end-organ manifestations such as glomerulonephritis or thrombosis ${ }^{(\mathbf{1})}$. It is an aggressive disease, in which organ damage can't be prevented. Rheumatologists should try hardly to control disease activity in order to minimize the damage ${ }^{(2)}$.

Lupus nephritis $(\mathrm{LN})$ is one of the commonest manifestations of SLE, occurring in about $50-70 \%$ of patients, and is a major cause of morbidity and mortality in these patients. The clinical course of $\mathrm{LN}$ is heterogeneous and varies from mild subclinical disease to an aggressive course that may rapidly progress to end-stage renal disease (ESRD) ${ }^{(3)}$. $\mathrm{LN}$ is characterized by a relapsing-remitting course, requiring constant follow-up and surveillance and often entailing changing treatments. Early clinical and histologic diagnosis of LN is pivotal in order to minimize the risk of progression to ESRD (4).

Renal biopsy is the gold standard for providing information on the histological classes of lupus nephritis and the relative degree of activity and chronicity in the glomeruli. However, it is invasive and serial biopsies are needed which is impractical in the monitoring of lupus nephritis. Thus, novel biomarkers that are able to discriminate lupus renal activity and its severity, predict renal flares, and monitor treatment response and disease progress are clearly necessary ${ }^{(5)}$.

A biomarker refers to a biologic, biochemical, or molecular event that can be assayed qualitatively and quantitatively by laboratory techniques. The levels of biomarkers should correlate with disease pathogenesis or activity in different organ systems ${ }^{(6)}$. A useful biomarker should be easy to assay, simple to interpret, and readily available in most laboratories with a reasonable cost ${ }^{(7)}$. Sensitive and specific clinical markers for the onset or relapse of renal disease activity in patients with SLE may allow earlier institution of treatment and even preventive strategies so that the efficacy of existing therapies can be enhanced while treatment-related complications can be minimized ${ }^{(8)}$.

Xu et al. (9), reported that current laboratory markers for $\mathrm{LN}$ such as proteinuria, urine protein-tocreatinine ratio, creatinine clearance, anti-dsDNA, and complement levels are unsatisfactory. They lack sensitivity and specificity for differentiating renal activity and damage in LN. Significant kidney damage can occur before renal function is impaired and first detected by laboratory parameters. With respect to $\mathrm{LN}$, urinary biomarkers may be more specific for kidney 
damage than serum biomarkers, particularly in SLE patients with active systemic disease.

Furthermore, obtaining urine for laboratory testing is much easier and less invasive, making urine a more ideal biological sample for a disease that requires repetitive screening ${ }^{(\mathbf{1 0})}$.

Tumor necrosis factor-like weak inducer of apoptosis (TWEAK) is a multifunctional cytokine that belongs to the TNF-ligand superfamily ${ }^{(6)}$. It may play an important pathogenic role in the development of GN by promoting a local inflammatory environment and inducing kidney cell proliferation ${ }^{(\mathbf{1 1})}$.

The aim of this work was to evaluate the role of urinary TWEAK (UTWEAK) as a biomarker for diagnosis and prognosis of lupus nephritis and its correlation with activity and chronicity index obtained by renal biopsy. Also, to evaluate the management plan in newly diagnosed cases with lupus nephritis as regard to renal biopsy and biomarkers.

\section{SUBJECTS AND METHODS}

This study was carried out in Rheumatology and Rehabilitation Department and Nephrology Unit Internal Medicine Department, Faculty of Medicine, Zagazig University Hospitals in Zagazig University.

This study was carried out on 75 individuals, 50 SLE patients, fulfilling the SLICC revision of the ACR classification criteria For SLE ${ }^{(\mathbf{1 2})}$.

They were divided into 25 SLE patients with lupus nephritis (group I), considered as (group Ia) newly diagnosed lupus nephritis patients before starting treatment and (group Ib) lupus nephritis patients after receiving treatment for three months, 25 SLE patients without nephritis (group II) and 25 age and sex matched apparently healthy control subjects (group III).

\section{Exclusion criteria:}

1. Patients associated with any other diseases lead to renal affection such as urinary tract infection, essential hypertension, diabetes mellitus, etc...

2. Patients with end stage renal disease.

\section{Assessment of patients:}

All patients were subjected to thorough history taking and clinical examination.

I) Total SLEDAI: Patients were assessed by SLE Disease activity index (SLEDAI-2K) score ${ }^{(\mathbf{1 3})}$.

II) Renal SLEDAI: Kidney disease activity was assessed by the renal SLEDAI (rSLEDAI) score that consists of the 4 kidney-related items of the SLEDAI$2 \mathrm{~K}$ (hematuria, pyuria, proteinuria and urinary casts). The presence of each one gives a score of 4 points; thus, the score can range from 0 (non-active renal disease) to a maximal score of $16^{(13)}$.

According to the rSLEDAI score the patients are then classified according to whether they are undergoing a renal flare or not. According to Schwartz and colleagues ${ }^{(14)}$ and Xuejing and colleagues ${ }^{(15)}$ any rSLEDAI score $\geq 4$ was considered as active LN.

III) Extra-renal SLEDAI: In the LN group, extra-renal disease activity (the extra-renal SLEDAI) was calculated by subtracting the renal SLEDAI score from the total SLEDAI score ${ }^{(\mathbf{1 6})}$.

IV) Renal biopsy: Were done for SLE patients who have confirmed proteinuria $>0.5 \mathrm{~g}$ in 24 -hour urine samples or active urinary sediment

(microhematuria/leukocyturia/casts) or inexplicable decrease in renal function ${ }^{(17)}$.

Renal biopsy specimens from LN patients were classified according to the International Society of Nephrology/Renal Pathology 2003 (ISN/RPS) ${ }^{(18)}$.

\section{V) Laboratory investigations:}

(a) Routine laboratory testing including: erythrocyte sedimentation rate (ESR), complete blood picture (CBC), complete urine analysis, estimation of total protein in urine in 24 hours, kidney function tests, liver function tests.

(b) Antinuclear antibodies (ANA) by immunofluorescence technique.

(c) Anti deoxyribonucleic acid (anti-DNA) antibodies by immunofluorescence technique.

(d) Quantitative determination of serum complements levels $(\mathrm{C} 3, \mathrm{C} 4)$.

(e) Urinary TWEAK (TWEAK) levels were measured by specific sandwich ELISA according to the instruction of the manufacturer (RayBioTech, Inc., USA) it is measured by collecting mid-stream urine samples under aseptic conditions, voided directly into a sterile container and centrifuged 20 minutes at speed 2000-3000 rpm to remove supernatant.

It was collected on biopsy day for the newly diagnosed LN group, on a day of clinic follow-up for this group after three months and on a day of clinic follow-up for non-renal group. Storage at $-20^{\circ} \mathrm{C}$ (without repeated freeze-thaw cycles).

\section{VI) Protocol of treatment for LN group (based on renal pathology):}

According to ACR Recommendations for the management of $\mathrm{LN}^{(\mathbf{1 9})}$ :

- Class I: Minimal mesangial LN require no specific therapy (20).

- Class II: Mesangial proliferative LN may require treatment if proteinuria is greater than $1000 \mathrm{mg} / \mathrm{d}$. Consider prednisone in low-to-moderate doses (i.e. 20-40 mg/d) for 1-3 months, with subsequent taper (20).

- Class III/IV lupus glomerulonephritis: Mycophenolate mofetil (MMF 2-3 grams total daily orally) or cyclophosphamide (CYC) high dose CYC (500-1000 mg/m² i.v. once a month for 
6 doses), followed by maintenance treatment with MMF or AZA ${ }^{(21)}$. Pulse i.v. glucocorticoids (500$1000 \mathrm{mg}$ methylprednisolone daily for 3 doses) followed by daily oral glucocorticoids $(0.5-1$ $\mathrm{mg} / \mathrm{kg} /$ day) followed by a taper to the minimal amount necessary to control disease.

- Class V "Pure membranous" Lupus Nephritis: Prednisone $(0.5 \mathrm{mg} / \mathrm{kg} / \mathrm{day})$ plus MMF $2-3 \mathrm{~g}$ total daily dose or i.v. CYC $(0.5-1.0 \mathrm{mg} / \mathrm{kg}$ i.v. monthly $\times 6$ ) plus prednisone.

\section{Monitoring and prognosis of $\mathbf{L N}$ :}

Complete renal response defined as: Proteinuria $<0.5 \mathrm{~g} / 24 \mathrm{~h}$. Normal or near-normal (within $10 \%$ of normal GFR if previously abnormal) GFR.

Partial renal response defined as: $\geq 50 \%$ reduction in proteinuria to subnephrotic levels. Normal or nearnormal GFR, should be achieved preferably by 6 months and no later than 12 months following treatment initiation ${ }^{(22)}$.

Nephritic flares include: Reproducible increase of serum creatinine by $\geq 30 \%$ (or, decrease in GFR by $\geq 10 \%$ ). Active urine sediment with increase in glomerular hematuria by $\geq 10$ red blood cells per high power field, irrespective of changes in proteinuria. Proteinuric flares include reproducible doubling of UPCR to $>100 \mathrm{mg} / \mathrm{mmol}$ after complete response or reproducible doubling of UPCR to $>200 \mathrm{mg} / \mathrm{mmol}$ after partial response ${ }^{(23)}$.

Ethics approval and consent to participate: Informed consents were obtained from all the participants.

The study was approved by the Institutional Review Board (IRB) of the Faculty of Medicine of Zagazig University.

\section{Statistical analysis}

All statistical analyses were performed with SPSS, version 21.0 (IBM Corp, NY, USA). Parametric quantitative data were presented by mean and standard deviation (SD) and non-parametric data were presented by median and range. T-test was used for comparison between two groups. Post hoc tests (LSD) were used to uncover specific significant differences between three or more group means.

Qualitative data were represented by frequency and percentage and were compared by $\mathrm{Chi}^{2}$ test. Results were considered significant if $\mathrm{P}$ value is $<0.05$ and highly significant if $\mathrm{P}$ value is $<0.001$. The ability of baseline uTWEAK to distinguish between SLE patients with or without nephritis, as well as the ability of baseline uTWEAK to identify the response to treatment were estimated by the receiver operating characteristic (ROC) curve analysis, area under curve (AUC) with 95\% confidence intervals (CIs).

\section{RESULTS}

There was no statistical significant difference as regard age and sex between studied groups (Table 1). In group I, according to renal biopsy, there were 3 patients (12\%) had class II, 7 (28\%) class III, 9 (36\%) class IV, and 3 patients $(12 \%)$ were diagnosed with class V LN. There were 3 patients (12\%) had membranoproliferative glomerulonephritis.

Twenty three patients had active lesions and 4 patients had chronic lesions. The median value of Activity Index (AI) and Chronicity Index (CI) were 10.12 and 2.06, respectively. 
Table (1): Demographic and clinical data among studied groups

\begin{tabular}{|c|c|c|c|c|c|c|c|}
\hline Demographic data & \multicolumn{2}{|c|}{$\begin{array}{l}\text { Group I } \\
25 \text { lupus } \\
\text { nephritis }\end{array}$} & \multicolumn{2}{|c|}{$\begin{array}{c}\text { Group II } \\
25 \text { non- renal } \\
\text { SLE }\end{array}$} & \multicolumn{2}{|c|}{$\begin{array}{c}\text { GIII } \\
\text { Control } 25\end{array}$} & $p$ \\
\hline $\begin{array}{l}\text { Age }(y) \\
\text { Mean +SD } \\
\text { Range }\end{array}$ & \multicolumn{2}{|c|}{$\begin{array}{c}26.8 \pm 7.1 \\
20-35\end{array}$} & \multicolumn{2}{|c|}{$\begin{array}{c}27.6 \pm 6.91 \\
18-39\end{array}$} & \multicolumn{2}{|c|}{$\begin{array}{c}27.1+6.5 \\
19-38\end{array}$} & $>0.05$ \\
\hline \multirow{2}{*}{$\begin{array}{l}\text { Sex } \\
\text {-Female } \\
\text {-Male }\end{array}$} & \multicolumn{2}{|c|}{$\mathbf{N}(\%)$} & \multicolumn{2}{|c|}{$\mathbf{N}(\%)$} & \multicolumn{2}{|c|}{$\mathbf{N}(\%)$} & \multirow[t]{2}{*}{$>0.05$} \\
\hline & \multicolumn{2}{|c|}{$\begin{array}{c}22(88.0 \%) \\
3(12.0 \%)\end{array}$} & \multicolumn{2}{|c|}{$\begin{array}{c}21(84.0 \%) \\
4(16.0 \%)\end{array}$} & \multicolumn{2}{|c|}{$\begin{array}{c}23(92.0 \%) \\
2(8.0 \%)\end{array}$} & \\
\hline \multirow[t]{3}{*}{ b ) Clinical data } & \multicolumn{4}{|c|}{ Group I } & \multirow{2}{*}{\multicolumn{2}{|c|}{$\begin{array}{c}\text { Group II } \\
25 \text { non renal SLE }\end{array}$}} & \multirow{3}{*}{$\begin{array}{c}P \text { of } \\
X^{2}\end{array}$} \\
\hline & \multicolumn{2}{|c|}{$\begin{array}{c}\text { GIa } \\
25 \mathrm{LN} \\
(\text { per ttt) }\end{array}$} & \multicolumn{2}{|c|}{$\begin{array}{c}G I b \\
25 \text { LN } \\
(\text { post ttt) }\end{array}$} & & & \\
\hline & $N$ & $\%$ & $N$ & $\%$ & $N$ & $\%$ & \\
\hline $\begin{array}{l}\text { Constitutional } \\
\text { Fever } \\
\text { Weight loss } \\
\text { Fatigue }\end{array}$ & $\begin{array}{c}17 \\
5 \\
16\end{array}$ & $\begin{array}{l}68.0 \\
20.0 \\
64.0\end{array}$ & $\begin{array}{c}8 \\
2 \\
14 \\
\end{array}$ & $\begin{array}{c}32.0 \\
8.0 \\
56.0\end{array}$ & $\begin{array}{c}14 \\
3 \\
15\end{array}$ & $\begin{array}{l}56.0 \\
12.0 \\
60.0\end{array}$ & $\begin{array}{l}>0.05 \\
>0.05 \\
>0.05\end{array}$ \\
\hline $\begin{array}{l}\text { Mucocutaneous } \\
\text { Malar rash } \\
\text { Photosensitivity } \\
\text { Oral ulcer } \\
\text { Alopecia }\end{array}$ & $\begin{array}{c}25 \\
23 \\
8 \\
19\end{array}$ & $\begin{array}{l}100.0 \\
92.0 \\
32.0 \\
76.0\end{array}$ & $\begin{array}{c}22 \\
20 \\
3 \\
8\end{array}$ & $\begin{array}{l}3.0 \\
80.0 \\
12.0 \\
32.0\end{array}$ & $\begin{array}{l}25 \\
21 \\
10 \\
21\end{array}$ & $\begin{array}{c}100.0 \\
84.0 \\
40.0 \\
84.0\end{array}$ & $\begin{array}{l}>0.05 \\
>0.05 \\
<0.04^{*} \\
<0.001^{*}\end{array}$ \\
\hline $\begin{array}{l}\text { Musculoskeletal } \\
\text { Arthralgia } \\
\text { Arthritis } \\
\text { Myalgia } \\
\text { Myositis }\end{array}$ & $\begin{array}{c}16 \\
9 \\
7 \\
0\end{array}$ & $\begin{array}{c}64.0 \\
36.0 \\
28.0 \\
0.0\end{array}$ & $\begin{array}{l}12 \\
4 \\
3 \\
0\end{array}$ & $\begin{array}{l}48.0 \\
16.0 \\
2.00 .0\end{array}$ & $\begin{array}{c}21 \\
18 \\
6 \\
0\end{array}$ & $\begin{array}{c}84.0 \\
72.0 \\
24.0 \\
0.0\end{array}$ & $\begin{array}{c}>0.05 \\
<0.001^{*} \\
>0.05 \\
----\end{array}$ \\
\hline $\begin{array}{l}\text { Vasculitis } \\
\text { Cutaneous } \\
\text { Raynaud's }\end{array}$ & $\begin{array}{l}0 \\
1\end{array}$ & $\begin{array}{l}0.0 \\
4.0\end{array}$ & $\begin{array}{l}0 \\
1\end{array}$ & \begin{tabular}{|l|}
0.0 \\
4.0
\end{tabular} & $\begin{array}{l}2 \\
4\end{array}$ & $\begin{array}{l}8.0 \\
16.0\end{array}$ & $\begin{array}{l}>0.05 \\
>0.05\end{array}$ \\
\hline $\begin{array}{l}\text { Pulmonary } \\
\text { Pleural affection } \\
\text { Interstitial fibrosis }\end{array}$ & $\begin{array}{l}4 \\
1\end{array}$ & $\begin{array}{r}16.0 \\
4.0\end{array}$ & $\begin{array}{l}1 \\
1\end{array}$ & $\begin{array}{l}4.0 \\
4.0\end{array}$ & $\begin{array}{c}13 \\
5\end{array}$ & $\begin{array}{l}(52.0) \\
(20.0)\end{array}$ & $\begin{array}{c}<0.001^{*} \\
>0.05\end{array}$ \\
\hline $\begin{array}{l}\text { Neurological } \\
\text { Stroke } \\
\text { Seizures } \\
\text { Psychosis } \\
\text { Mood disturbance }\end{array}$ & $\begin{array}{l}0 \\
3 \\
0 \\
1\end{array}$ & $\begin{array}{l}0.0 \\
12.0 \\
0.0 \\
4.0\end{array}$ & $\begin{array}{l}0 \\
1 \\
0 \\
1\end{array}$ & $\begin{array}{l}0.0 \\
4.0 \\
0.0 \\
4.0\end{array}$ & $\begin{array}{l}1 \\
2 \\
3 \\
5\end{array}$ & $\begin{array}{r}4.0 \\
8.0 \\
12.0 \\
20.0\end{array}$ & $\begin{array}{l}>0.05 \\
>0.05 \\
>0.05 \\
>0.05\end{array}$ \\
\hline $\begin{array}{l}\text { Hematological } \\
\text { Anemia } \\
\text { Leucopenia } \\
\text { Thrombocytopenia } \\
\text { Pancytopenia }\end{array}$ & $\begin{array}{l}20 \\
7 \\
5 \\
5 \\
\end{array}$ & $\begin{array}{l}80.0 \\
28.0 \\
20.0 \\
20.0\end{array}$ & $\begin{array}{l}16 \\
5 \\
3 \\
3 \\
\end{array}$ & $\begin{array}{l}64.0 \\
20.0 \\
12.0 \\
12.0\end{array}$ & $\begin{array}{c}13 \\
5 \\
2 \\
2 \\
\end{array}$ & $\begin{array}{r}52.0 \\
20.0 \\
8.0 \\
8.0 \\
\end{array}$ & $\begin{array}{l}0.03 * \\
>0.05 \\
>0.05 \\
>0.05\end{array}$ \\
\hline $\begin{array}{l}\text { Cardiac } \\
\text { Valvular } \\
\text { Pericardiac }\end{array}$ & $\begin{array}{l}4 \\
2 \\
\end{array}$ & $\begin{array}{l}16.0 \\
8.0\end{array}$ & $\begin{array}{l}4 \\
1 \\
\end{array}$ & $\begin{array}{c}16.0 \\
4.0\end{array}$ & $\begin{array}{l}3 \\
1 \\
\end{array}$ & $\begin{array}{r}12.0 \\
4.0 \\
\end{array}$ & $\begin{array}{l}>0.05 \\
>0.05\end{array}$ \\
\hline
\end{tabular}

In this study, u TWEAK level showed a highly statistical significant difference among groups. A statistically significant lower uTWEAK levels in SLE patients without kidney involvement (group II) and normal healthy subjects (group III), as compared to LN patients (group I) and statistically significant lower uTWEAK levels in LN patients (Post ttt) (group Ib) compared with those with LN patients (Pre ttt) (group Ia) (Table 2). 
Table (2): The uTWEAK level among studied group

\begin{tabular}{|c|c|c|c|c|c|c|}
\hline 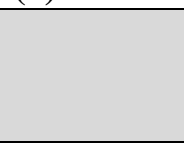 & $\begin{array}{c}\text { Group Ia } \\
25 \text { LN } \\
\text { (pre ttt) }\end{array}$ & $\begin{array}{c}\text { Group Ib } \\
25 \text { LN } \\
\text { (post ttt) }\end{array}$ & $\begin{array}{c}\text { Group II } \\
5 \text { non renal SLE }\end{array}$ & $\begin{array}{l}\text { Group III } \\
\text { control } 25\end{array}$ & $P$ & $L S D$ \\
\hline $\begin{array}{l}\text { uTWEAK } \\
\text { (pg/mg } \\
\text { Cr.) } \\
\text { Median } \\
\text { Range }\end{array}$ & $\begin{array}{c}29.64 \\
9.76-38.18\end{array}$ & $\begin{array}{c}15.47 \\
2.83-27.27\end{array}$ & $\begin{array}{c}4.56 \\
1.29-10.2\end{array}$ & $\begin{array}{c}3.8 \\
0.78-8.1\end{array}$ & $<0.001 *$ & $\begin{array}{c}0.04^{\mathrm{a}} \\
0.00^{\mathrm{b}} \\
0.00^{\mathrm{c}} \\
0.02^{\mathrm{d}} \\
0.00^{\mathrm{e}} \\
>0.05^{\mathrm{f}}\end{array}$ \\
\hline
\end{tabular}

(a) Group $I a$ versus Group $I b$, (b) Group Ia versus Group II, (c) Group Ia versus Group III

(d) Group $I b$ versus Group II, (e) Group $I b$ versus Group III, (f) Group II versus Group III

-LSD $=$ Least Significant Difference $-\mathrm{P}$ value statistical significance $(\leq 0.05)$

A)

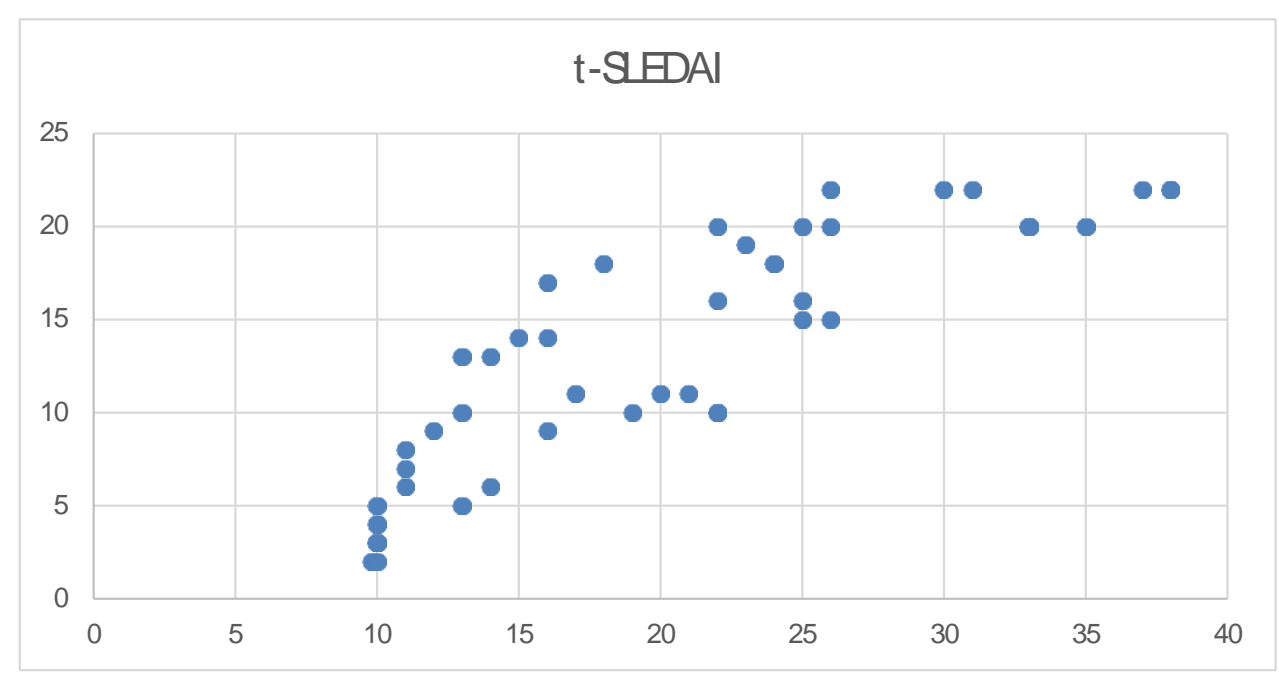

B)

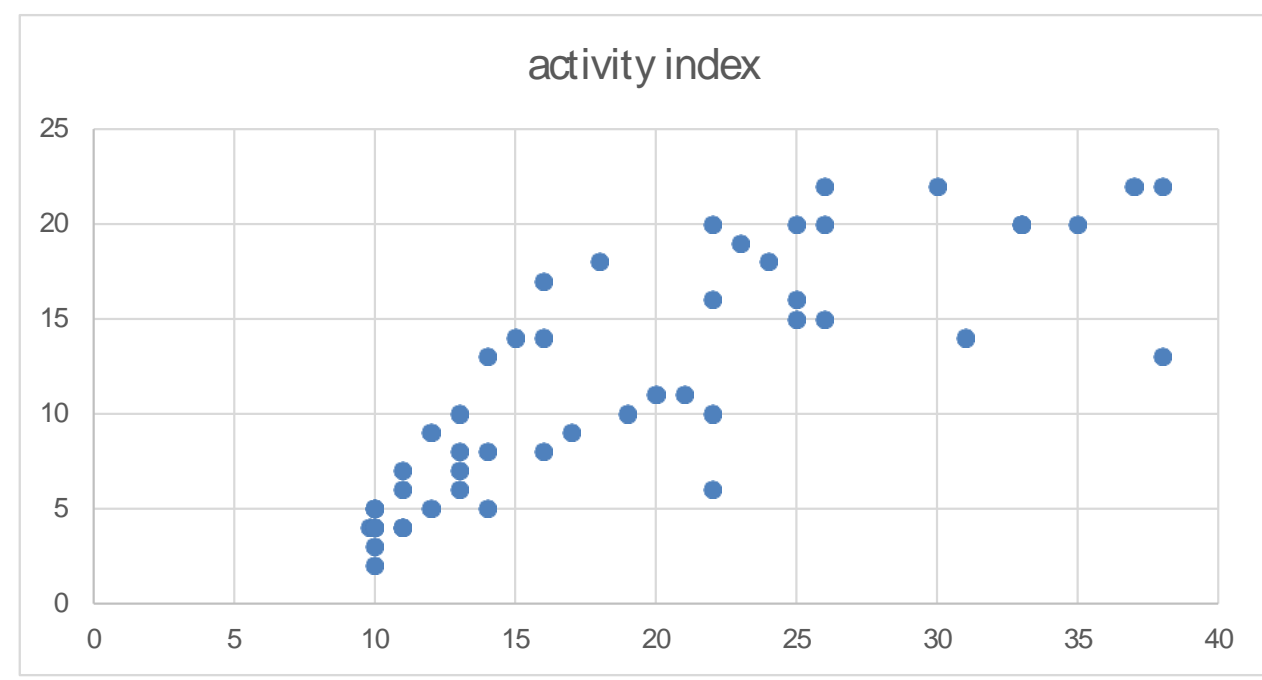

Figure (1): (A) Correlation between uTWEAK and SLEDAI of SLE patients.

(B) Correlation between uTWEAK and histopathological activity

There was direct highly significant correlations between uTWEAK and tSLEDAI $(\mathrm{r}=0.58, \mathrm{P}<0.001)$ (Fig. 1-A) and rSLEDAI ( $\mathrm{r}=0.73, \mathrm{P}<0.001)$. However, there was no significant correlation between UTWEAK levels and extra renal SLEDAI $(r=0.11, \mathrm{P}=0.37)$.

The urinary TWEAK levels of patients with LN had significantly positive correlation with Active Index
(AI) (Fig. 1-B) but had no significant correlation $(P>0$. 05) with Chronicity Index (CI).

Urinary TWEAK had significant association with the presence of proliferative GN (Class III, IV) ( $\mathrm{p}=$ $0.003)$ but had no significant association $(P>0.05)$ with non-proliferative GN. 
In figure (2), we demonstrated renal biopsies of two patients included in the study. Figure 2A demonstrates a patient with focal proliferative glomerulonephritis (Class III). This patient had proteinuria $2100 \mathrm{mg} / 24$ hours, normal serum creatinine, normal blood pressure and low levels of $\mathrm{C} 3$ and $\mathrm{C} 4$. Figure $2 \mathrm{~B}$ demonstrates a patient with active diffuse proliferative lupus nephritis (Class IV). This patient had proteinuria $2900 \mathrm{mg} / 24$ hours, RBC casts in urine, normal serum creatinine, high blood pressure and low levels of C3and C4.

All SLE patients $(100 \%)$ were treated with oral steroids in different doses. Sixty eight percent of lupus nephritis patients (group I) were treated with IV methylprednisolone. All lupus nephritis (100\%) and 23 non renal SLE patients (92\%) were treated with hydroxychloroquine. Fourteen lupus nephritis patients $(56 \%)$ were treated with cyclophosphamide, while 8 lupus nephritis patients (32\%) were treated with MMF. Three patients (12\%) in (group I) and 20 patients (80\%) in (group II) were treated with azathioprine. There was a statistical significant difference between patients in responding to cyclophosphamide and mycophenolate mofetil regarding to pyuria, hematuria, proteinuria and uTWEAK (Table 3).

A)

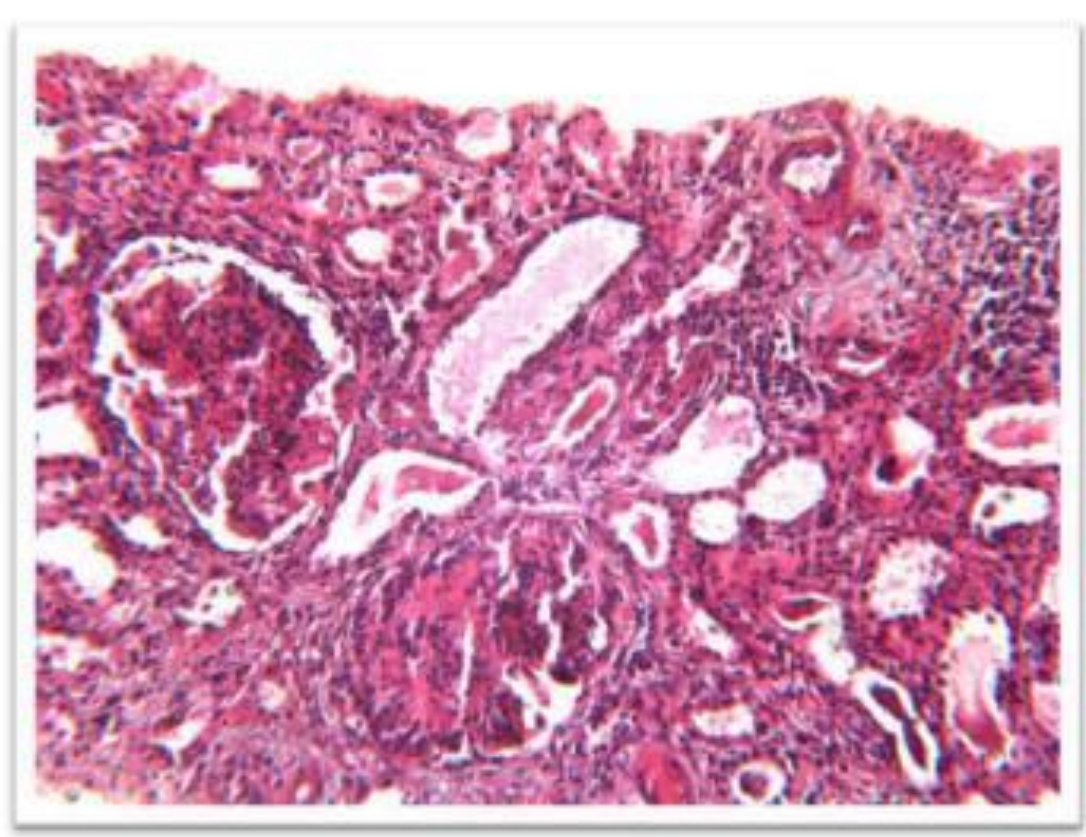

B)

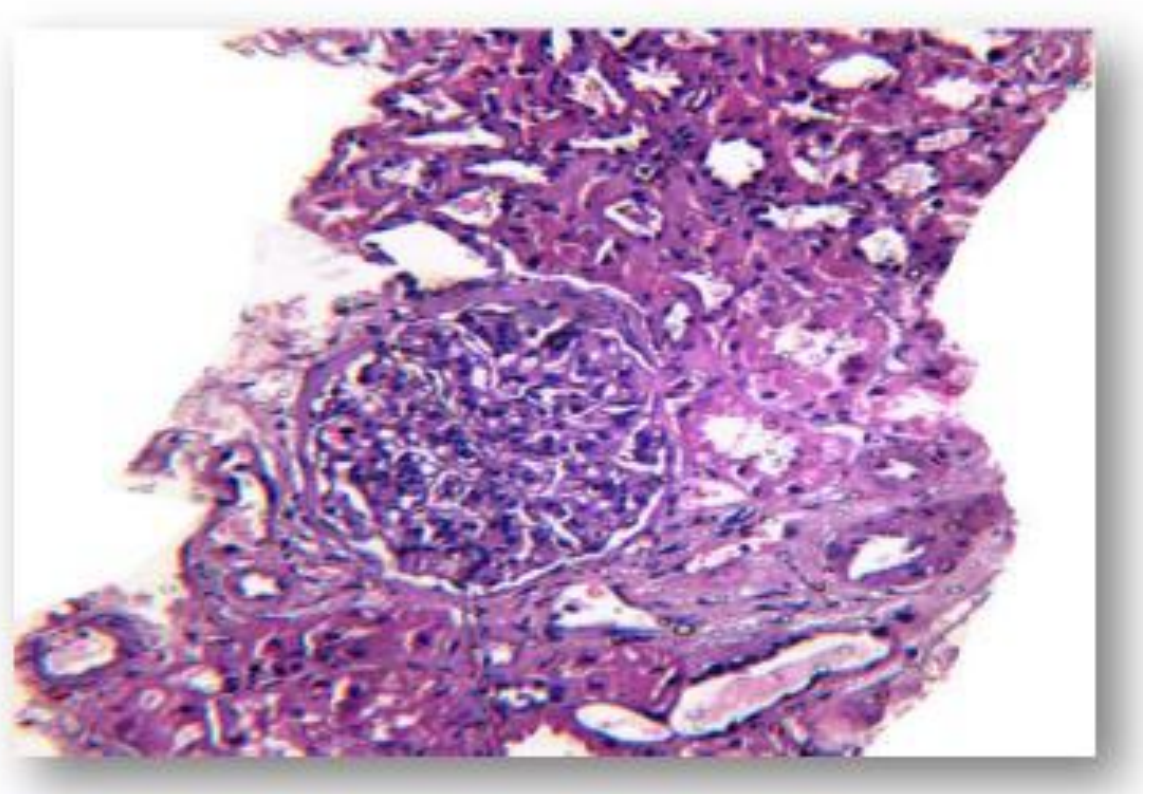

Figure (2): (A) Focal proliferative glomerulonephritis (Class III).

(B) Active, diffuse proliferative lupus nephritis (Class IV). 
Table (3): The effect of drugs on patients with LN group

\begin{tabular}{|c|c|c|c|c|c|c|}
\hline & $\begin{array}{c}\text { GIa } \\
14 \text { lupus } \\
\text { nephritis } \\
\text { (pre ttt) }\end{array}$ & $\begin{array}{c}\text { GIb } \\
14 \text { lupus } \\
\text { nephritis (post } \\
\text { ttt) }\end{array}$ & $\mathbf{P}$ & $\begin{array}{c}\text { GIa } \\
8 \text { lupus } \\
\text { nephritis (pre } \\
\text { ttt) } \\
\end{array}$ & \begin{tabular}{|c}
$G I b$ \\
8 lupus \\
nephritis \\
(post ttt)
\end{tabular} & $\mathbf{P}$ \\
\hline & \multicolumn{3}{|c|}{ Cyclophosphamide (14 patients) } & \multicolumn{3}{|c|}{ Mycophenolate mofetil (8 patients) } \\
\hline Pyuria & $8(57.1 \%)$ & $3(21.9 \%)$ & $0.048^{*}$ & $5(62.5)$ & $1(12.5)$ & $0.03^{*}$ \\
\hline Hematuria & $4(28.5 \%)$ & $2(14.28 \%)$ & $0.028^{*}$ & $1(12.5)$ & $0(0.0)$ & $>0.05$ \\
\hline Cast & $2(14.28 \%)$ & $1(7.19 \%)$ & $>0.05$ & $4(50.0)$ & $1(12.5)$ & $0.03^{*}$ \\
\hline \begin{tabular}{|c}
24 hours Ur. Proteins (gm) \\
$>3 \mathrm{gm}$ \\
$1-3 \mathrm{gm}$ \\
$<1 \mathrm{gm}$ \\
\end{tabular} & \begin{tabular}{|l|}
$3(21.9 \%)$ \\
$8(57.1 \%)$ \\
$3(21.9 \%)$ \\
\end{tabular} & $\begin{array}{l}2(14.28 \%) \\
5(35.7 \%) \\
7(50.0 \%) \\
\end{array}$ & $0.02 *$ & $\begin{array}{c}4(50.0) \\
4(50.0) \\
0(0.0) \\
\end{array}$ & $\begin{array}{l}2(25.0) \\
5(62.5) \\
1(12.5) \\
\end{array}$ & $0.04^{*}$ \\
\hline $\begin{array}{c}\text { u TWEAK }(p g / m g \text { Cr. }) \\
\text { Median } \\
\text { Range }\end{array}$ & $\begin{array}{c}26 \\
9.8-35.3 \\
\end{array}$ & $\begin{array}{c}10 \\
4.3-27.8 \\
\end{array}$ & $0.04 *$ & $\begin{array}{c}28 \\
11-38.8 \\
\end{array}$ & $\begin{array}{c}11 \\
2.8-22.4 \\
\end{array}$ & $0.04 *$ \\
\hline $\begin{array}{c}\text { GFR } \\
>60 \mathrm{~mL} / \mathrm{min} \\
<60 \mathrm{~mL} / \mathrm{min}\end{array}$ & $\begin{array}{c}11(78.5) \\
3(21.5)\end{array}$ & $\begin{array}{l}12(85.7 \%) \\
2(14.28 \%)\end{array}$ & $>0.05$ & $\begin{array}{l}4(50.0) \\
4(50.0)\end{array}$ & $\begin{array}{l}6(75.0) \\
2(25.0)\end{array}$ & $>0.05$ \\
\hline
\end{tabular}

GFR: glomerular filtration rate

There was a statistical significant difference between improved and poor responder patients as regard to uTWEAK level (table 4).

Table (4): Difference in baseline uTWEAK levels between improved and non-improved LN patients

\begin{tabular}{|c|c|c|c|}
\hline & $\begin{array}{c}\text { Improved } \\
\text { No=18 }\end{array}$ & $\begin{array}{c}\text { Poor Response } \\
\text { No=7 }\end{array}$ & $P$ \\
\hline $\begin{array}{c}\text { uTWEAK }(\mathrm{pg} / \mathrm{mg} \mathrm{Cr} .) \\
\text { Mean } \pm \text { SD }\end{array}$ & $19.7 \pm 4.8$ & $28.9 \pm 6.9$ & $0.03^{*}$ \\
\hline
\end{tabular}

Receiver operating characteristic (ROC) curve was done to show the ability of baseline uTWEAK to distinguish between SLE patients with or without nephritis and identify their response to treatment. At cutoff point $\geq 9.9 \mathrm{pg} / \mathrm{mg}$ Cr, uTWEAK had sensitivity of $76 \%$ and a specificity of $60 \%$ to diagnose SLE patients with nephritis (AUC $=0.55$ ). At cutoff point of $\leq 14.9 \mathrm{pg} / \mathrm{mg} \mathrm{Cr}$, the uTWEAK level had a sensitivity of $88 \%$ and a specificity of $76 \%$ to predict good response to treatment in $\mathrm{LN}$ patients $(\mathrm{AUC}=0.954)($ Fig. 3$)$. 
A)

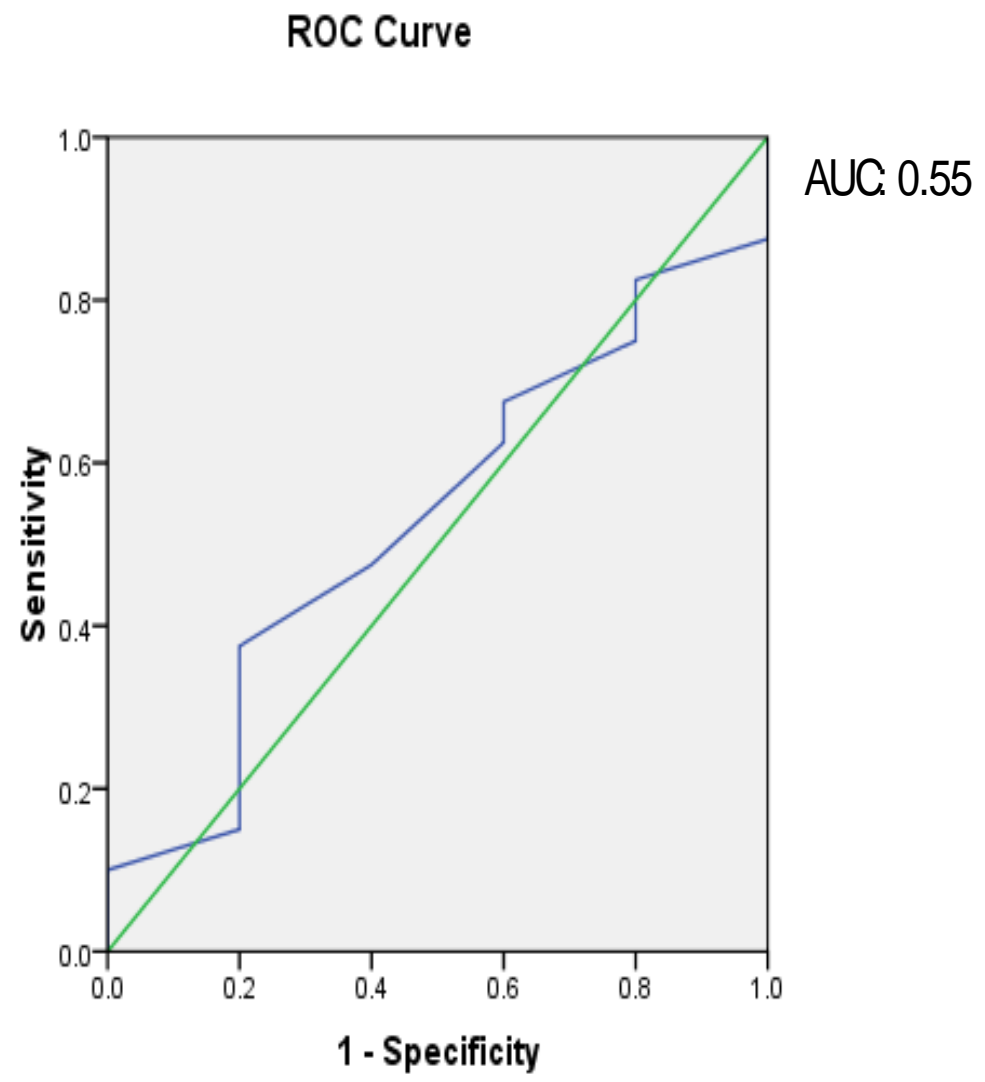

Diagonal segments are produced by ties.

B)

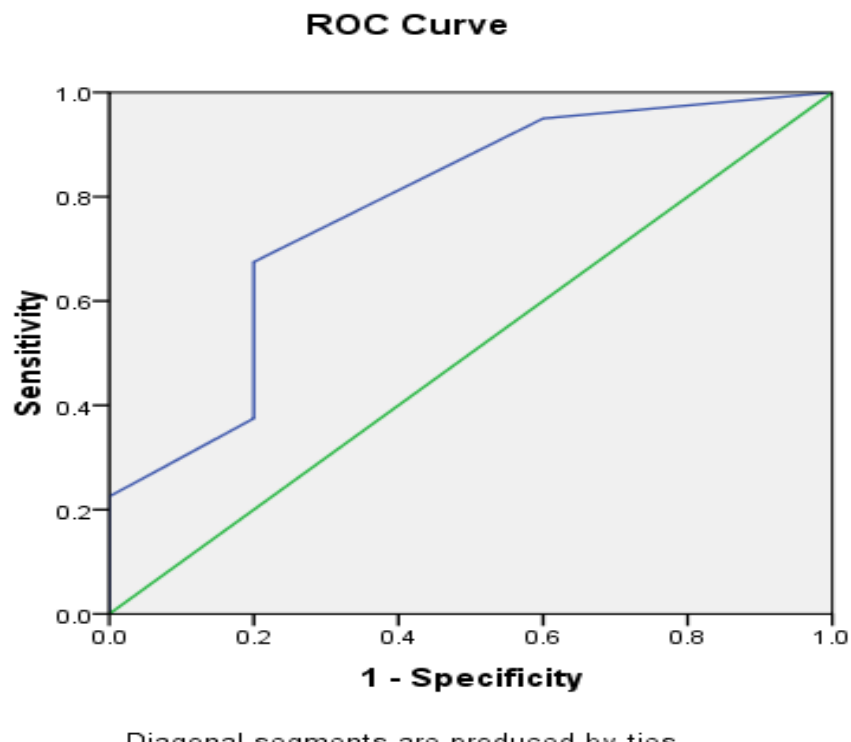

AUC. 0.954

Figure (3): (A) The ability of baseline UTWEAK to distinguish between SLE patients with or without nephritis. (B) The ability of baseline uTWEAK to identify the response to treatment. 


\section{DISCUSSION}

Systemic lupus erythematosus (SLE) is a systemic autoimmune disease in which diverse immunological events can lead to a similar clinical picture, characterized by a wide range of clinical manifestations and target organ involvement with unpredictable flares and remissions that eventually lead to permanent injury ${ }^{(24)}$.

LN is one of the most serious SLE complications since it is the major predictor of poor prognosis. About $50-80 \%$ of patients with lupus suffer from $\mathrm{LN}$ and up to $25 \%$ of these patients still develop end-stage renal disease (ESRD) 10 years after onset of renal compromise ${ }^{(25)}$. In terms of outcome, lupus nephritis is associated with a 6-fold increase in mortality compared with the general population. Lupus patients who develop ESRD have a 26-fold excess in the risk of death, which is more than twice the risk associated with malignancy or cardiovascular disease in these patients ${ }^{(26)}$.

Renal biopsy remains the gold standard to accurately diagnose lupus nephritis stages, but multiple biopsies to gauge treatment efficacy are not feasible because of their invasive nature. It has thus become clear that there is a real need for surrogate markers that can predict the degree of renal inflammation ${ }^{(5)}$.

Persistent proteinuria may not necessarily indicate ongoing inflammation in the kidneys and may be contributed by pre-existing chronic lesions or recent damage in the kidneys during the course of the disease. Flares of nephritis can occur without any observable and recent increase in the degree of proteinuria ${ }^{(26)}$. Cystatin $\mathrm{C}$ is a biomarker with sensitivity higher than that of creatinine, but it added no more benefit in the routine assessment of GFR in SLE patients ${ }^{(27)}$.

Mok ${ }^{(6)}$ reported that an ideal biomarker for LN should possess the following properties: good correlation with renal activity, sensitive to change so that it can be used for serial monitoring of disease activity, has the ability to predict renal activity/flares before an obvious change in conventional clinical parameters occurs, specific to nephritis among patients with SLE and specific to SLE for aiding early diagnosis of LN.

Wen et al. ${ }^{(7)}$ reported that cytokines and chemokines secreted locally within the kidney are instrumental in the pathogenesis of LN. Furthermore, cytokines and chemokines excreted in the urine are an excellent indicator of their local production and secretion, and thus may have more potential than a serum-based marker to reflect inflammatory activity in the kidney. With respect to LN, urinary biomarkers may be more specific for kidney damage than serum biomarkers, particularly in SLE patients with active systemic disease. Furthermore, obtaining urine for laboratory testing is much easier and less invasive, making urine a more ideal biological sample for a disease that requires repetitive screening ${ }^{(28)}$.
In this study, uTWEAK level showed statistically significant lower uTWEAK levels in SLE patients without kidney involvement and normal healthy subjects, compared with LN patients, and statistically significant lower uTWEAK levels in patients (Post ttt), compared with those with LN patients (Pre ttt).

Similar results were found by Schwartz and colleagues who reported that a comparison between uTWEAK levels of LN patients and the control groups yielded an overall significant difference $(\mathrm{P}=0.039)$. Post-hoc testing revealed statistically significant lower uTWEAK levels in the SLE non-LN patient, healthy control, and RA patient, compared with the LN group. This indicates that high uTWEAK levels are a relatively unique feature of $\mathrm{LN}$ and are neither due to the systemic inflammatory process (as occurs in non-LN SLE patients or in RA patients) nor the renal disease in isolation ${ }^{(14)}$. Other studies, also, reported the same results ${ }^{(15)}$.

Also we found that uTWEAK levels were significantly positively correlated with tSLEDAI scoring system. However, the correlation of tSLEDAI scoring system with uTWEAK levels was discovered to be false positive as when only the extrarenal SLEDAI was considered, there was no significant correlation between uTWEAK and extrarenal SLEDAI. This strongly implies that the association of UTWEAK with active lupus disease was primarily dependent on the renal components of the score as in our finding there was a significant positive correlation between uTWEAK levels and rSLEDAI.

The same data were also reported by Elshehaby et al. ${ }^{(29)}$, they found that urinary levels of TWEAK, OPG, and MCP-1 positively correlate with rSLEDAI with reasonable sensitivity, specificity, and predictive values to detect the activity of LN.

All of the above mentioned studies were performed on SLE patients of multiple ethnicities and found that uTWEAK levels were significantly higher in SLE patients with active LN compared to the other groups indicating that uTWEAK played an important role in the active $\mathrm{LN}$ of different populations.

A comparison of UTWEAK level with different WHO classes of LN yielded no significant difference between the groups $(p=0.057)$. Similar results were found by Schwartz et al. ${ }^{(14)}$ and Almaani et al. ${ }^{(30)}$. This is a common problem in LN biomarker studies. The problem probably relates to the small number of subjects studied who are then sub-grouped into a number of histological classes, the inherent sampling error associated with renal biopsy, and the lack of a clear system to assess inflammatory disease activity at the tissue level ${ }^{(31)}$. This indicates that urinary UTWEAK detection cannot replace renal biopsy entirely in diagnostic process. This finding needs to be confirmed in larger numbers of patients displaying each of these histological subtypes. 
However, we found that UTWEAK showed significantly positive association with the presence of proliferative GN (Class III and IV) in renal biopsy. Other studies reported that the level of uTWEAK were higher in patients with Class V LN ${ }^{(32)}$.

uTWEAK levels showed significantly positive correlation with the histological renal activity index, but not renal chronicity index. This confirms that the elevation of uTWEAK level shows a stronger association with the renal disease activity rather than with the degree of renal insufficiency. So, uTWEAK levels may be used to monitor the renal disease activity without the need of repeating renal biopsy which is an invasive procedure to monitor the renal disease affection.

Similar results were found by Xuejing et al. ${ }^{(15)}$ who also found that uTWEAK levels correlated directly with the index of total activity and the index of glomerular and tubuleinterstitial activity, but not with the index of chronicity. Another study reported that the uTWEAK levels of patients with LN had significantly positive correlation with activity index, but had no significant correlation with chronicity index ${ }^{(33)}$.

Regarding the treatment protocol, we found that, MMF 2-3 g/day seems to be effective as IV pulses CYC (0.5 to $1.0 \mathrm{~g} / \mathrm{m}^{2}$ monthly) in combination with steroid in inducing remission in the majority of patients with active classes III, IV, and V LN as there was nonsignificant difference between two line of treatment.

Similar results were found by Satish et al. ${ }^{(34)}$ who concluded that MMF is as good as i.v. CYP in the induction therapy of $\mathrm{LN}$ in Indian patients. In contrast to our study, Ginzler et al. ${ }^{(35)}$ compared MMF with i.v. CYP and reported that MMF was significantly superior to CYP (22.5\% vs $5.8 \%$ complete remission). The study was performed on Caucasian and Afro-American patients. Patients with severe disease and chronicity were also included and hence the low rates of response in this study.

Comparison of uTWEAK level according to patients' response to treatment revealed a statistically significant difference, with a higher mean value in poor responders.

In a study in 2011 reported that the baseline uTWEAK levels were higher in non-responder LN compared with responders LN ${ }^{(29)}$. So uTWEAK may be a biomarker that detect prognosis and guide treatment of lupus nephritis patients. Targeting TWEAK protein in active lupus nephritis is an interesting choice of therapy.

The ability of uTWEAK to distinguish between SLE patients with or without nephritis had $76 \%$ sensitivity and $60 \%$ specificity.

These results were, nearly, similar to Elshehaby et al. ${ }^{\left({ }^{(29)}\right.}$ who reported that UTWEAK showed sensitivity of $89 \%$ and specificity of $56 \%$. A more recent study reported that the sensitivity and specificity of uTWEAK as a marker of nephritis in SLE patients had $100 \%$ sensitivity and $66.67 \%$ specificity ${ }^{(30)}$. On the contrary, Schwartz et al. ${ }^{(14)}$ reported that UTWEAK showed sensitivity of 50\% and specificity of $90 \%$.

The ability of uTWEAK to predict the response to treatment in $\mathrm{LN}$ patients had a sensitivity of $88 \%$ and specificity of $76 \%$. Similar results were found by Reyes-Martínez et al. ${ }^{(33)}$ who reported that uTWEAK showed sensitivity of $81 \%$ and specificity of $75 \%$.

From the collected data in our study, we can conclude that UTWEAK is a candidate biomarker for $\mathrm{LN}$ activity as it possesses the following properties:

1. Good correlation with renal activity as reflected by the degree of proteinuria and urine sediments.

2. Correlates with proliferative types of LN.

3. Sensitive to change so that it can be used for serial monitoring of disease activity in the kidneys and defining treatment response and clinical remission.

4. Ability to predict response to treatment.

\section{CONCLUSION}

We can use uTWEAK as a biomarker for detection of LN activity and prognosis in different situations in which it is difficult to ensure the presence of renal disease activity as during pregnancy, especially if the patient is suspected to have preeclampsia, or in the postpartum period.

Analysis of uTWEAK levels in an expanded panel of patients followed longitudinally with particular focus on measurements prior to clinical evidence of disease activity as well as correlations with patients' response to a given therapy, together with measurements of other emerging biomarkers, will help define a role for the serial measurement of UTWEAK levels in the clinical management of lupus patients with suspected or existing renal involvement.

Finally, uTWEAK levels may also be useful in the future to identify potential candidates for therapies intended to block the TWEAK signaling pathways.

\section{REFERENCES}

1. Gupta R, Aggarwal A, Sinha S et al. (2016): Urinary osteoprotegerin: a potential biomarker of lupus nephritis disease activity. Lupus, 25(11):1230-1236.

2. Hammad M, Eissa M, Fathi S (2016): Possible risk factors associated with greater damage in systemic lupus erythematosus patients: an Egyptian multicenter study. Lupus, 25(9):1019-27.

3. Borchers A, Leibushor $\mathbf{N}$ et al. (2012): Lupus nephritis: a critical review, Autoimmun Rev., 12(2):174-194.

4. Masood S, Jayne D, Karim Y (2009): Beyond immunosuppression challenges in the clinical management of lupus nephritis. Lupus, 18:106-115.

5. Liu C, Kao A, Manzi S et al. (2013): Biomarkers in systemic lupus erythematosus: challenges and prospects for the future. Ther Adv Musculoskelet Dis., 5(4): 210-233. 
6. Mok C (2010): Biomarkers for Lupus Nephritis: A Critical Appraisal. J Biomed Biotech, 10: 638413.

7. Wen $X$, Zheng Y, Chen $S$ et al. (2013): Clinical significance of neutrophil gelatinase-associated lipocalin, monocyte chemoattractant protein-1 and tumor necrosis factor-like apoptosis weak inducer in patients with systemic Iupus erythematosus. Chin J Rheumatol., 9: 611-615.

8. Gao H, Campbell S, Burkly L et al. (2009): TNF-like weak inducer of apoptosis (TWEAK) induces inflammatory and proliferative effects in human kidney cells. Cytokine, 46(1):24-35.

9. Xu X, Zheng M, Liu B (2016): Urinary TWEAK/Fn14 mRNA as a biomarker of lupus nephritis activity, Int $\mathbf{J}$ Clin Exp Med., 9(6):11236-11243.

10. Brunner H, Bennett $M$, Abulaban $K$ et al. (2016): Development of a novel renal activity index of lupus nephritis in children and young adults. Arthritis Care Res (Hoboken), 68(7):1003-1011.

11. Stock A, Wen J, Putterman C (2013): Neuropsychiatric lupus, the blood brain barrier, and the TWEAK/Fn14 Pathway. Frontiers in Immunology, 4:484-93.

12. Petri M, Orbai A, Alarcón G et al. (2012): Derivation and validation of systemic lupus international collaborating clinics classification criteria for systemic lupus erythematosus. Arth Rheum., 64(8): 2677-2686.

13. Gladman D, Ibanez D, Urowitz M (2002): Systemic lupus erythematosus disease activity index 2000. J Rheumatol., 29(2): 288-291.

14. Schwartz N, Rubinstein T, Burkly L et al. (2009): Urinary TWEAK as a biomarker of lupus nephritis: a multicenter cohort study. Arthritis Res Ther., 11(5): 143-149.

15. Xuejing Z, Jiazhen T, Jun L et al. (2012): Urinary TWEAK level as a marker of lupus nephritis activity in 46 cases. https://www.hindawi.com/journals/bmri/2012/359647/

16. Pitashny M, Schwartz N, Qing $X$ et al. (2007): Urinary lipocalin- 2 is associated with renal disease activity in human lupus nephritis. Arth Rheum., 56(6):1894-1903.

17. Rivera L, Belmont M, Malani S et al. (2009): Current therapies for lupus nephritis in an ethnically heterogeneous cohort. Kidney Int., 35(6):1193-1206.

18. Weening J, D'Agati V, Schwartz M et al. (2004): The classification of glomerulonephritis in systemic lupus erythematosus revisited. Kidney Int., 65(5): 521-530.

19. Hahn B, McMahon M, Wilkinson A et al. (2012): American college of rheumatology guidelines for screening, treatment, and management of lupus nephritis. Arthritis Care Res (Hoboken), 64(6):797808.

20. Dooley M (2007): Clinical and laboratory features of lupus nephritis. In: Dubois' Lupus Erythematosus. $7^{\text {th }}$ ed. Wallace DJ, Hahn BH, eds. Philadelphia, PA: Lippincott Williams \& Wilkins, Pp. 1112-1130.

21. Contreras G, Pardo V, Leclercq B et al. (2004): Sequential therapies for proliferative lupus nephritis. N Engl J Med., 350(10):971-980.
22. Reich H, Gladman D, Urowitz M et al. (2011): Persistent proteinuria and dyslipidemia increase the risk of progressive chronic kidney disease in lupus erythematosus. Kidney Int., 79(8):914-20.

23. Mak A, Cheung B, Mok C et al. (2006): Adrenomedullin - a potential disease activity marker and suppressor of nephritis activity in systemic lupus erythematosus. Rheumatology (Oxford), 45(10):12661272.

24. Salgado A, Herrera-Diaz C (2012): Lupus nephritis: An overview of recent findings. Hindawi Publishing Corporation. https://pubmed.ncbi.nlm.nih.gov/22536486/

25. Imran T, Yick F, Verma S et al. (2016): Lupus nephritis: an update. Clin Exp Nephrol., 20(1):1-13.

26. Hanly J, O'Keeffe A, Su L et al. (2016): The frequency and outcome of lupus nephritis: results from an international inception cohort study. Rheumatology (Oxford), 2:252-262.

27. El-Shafey A, Hammad M, Sharaf D et al. (2015): Evaluation of serum cystatin $\mathrm{C}$ as a marker of glomerular filtration rate in patients with systemic lupus erythematosus. Int J Adv Res., 3(5): 372-380.

28. Suttichet T, Saetang T, Anutrakulchai S et al. (2017): 320Urine TWEAK protein is a novel biomarker for resistant-to-treat lupus nephritis. Lupus, 4(1):227228.

29. El-shehaby A, Darweesh H, El-Khatib M et al. (2011): Correlations of urinary biomarkers, TNF-Like Weak Inducer of Apoptosis (TWEAK), Osteoprotegerin (OPG), Monocyte Chemoattractant Protein-1 (MCP-1), and IL-8 with Lupus Nephritis. J Clin Immunol., 31(5):848-856.

30. Almaani S, Meara A, Rovin B (2016): Update on lupus nephritis. Clin J Am Soc Nephrol., 12(5):825835.

31. Dhaun N, Kluth D (2009): TWEAK: a novel biomarker for lupus nephritis? Arthritis Res Ther., 11(6):133-137.

32. Urrego T, Ortiz-Reyes B, Aroca G et al. (2017): AB0538 Urinary levels of vcam-1 and tweak as biomarkers of lupus nephritis. Ann Rheum Dis., 76 (2) 538-541.

33. Reyes-Martínez F, Pérez-Navarro M, RodríguezMatías A et al. (2018): Assessment of urinary TWEAK levels in Mexican patients with untreated lupus nephritis: An exploratory study. Nefrologia., 38(2): 152-160.

34. Satish S, Deka P, Shetty M (2017): A clinicopathological study of lupus nephritis based on the International Society of Nephrology-Renal Pathology Society 2003 classification system. J Lab Physicians, 9:149-155.

35. Ginzler E, Dooley M, Aranow C et al. (2005): Mycophenolate mofetil or intravenous cyclophosphamide for lupus nephritis. N Engl J Med., 353(21):2219-2228. 